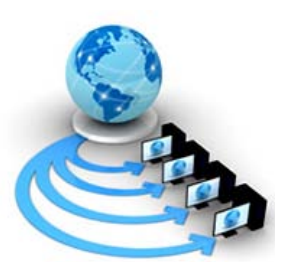

International Journal of Advanced Research in Computer Science

RESEARCH PAPER

Available Online at www.ijarcs.info

\title{
HYBRID APPROACH USING GAME THEORY AND IOT FOR DISEASE DETECTION AND REROUTING
}

\author{
Kanchan Jyoti \\ Mtech Scholar \\ SSIET,Dinanagar,India
}

\author{
Aastha Mahajan \\ H.O.D Computer Science \\ SSIET,Dinanagar,India
}

\begin{abstract}
Healthcare industry has never-endingly been on the bleeding edge in the selection and usage of data and correspondence advancements (ICT) for the effective medicinal services organization and treatment. Late improvements in ICT and the development of Internet of Things (loT) have opened up new roads for research and investigation in all the fields including medicinal and human service industry. Doctor's facilities have begun utilizing the cell instruments for correspondence aim and for this plan understudy Internet of things (loT) has been utilized and combined with wi-fi sensor hub reminiscent of game theory, NFC tag and little sensor hubs. The use of a cell specialist in social insurance methodology underneath wi-fi group condition allows to investigate enhanced administrations for patients and staffs reminiscent of therapeutic experts and medical caretakers given that of its versatility. A Noval Technqiue hybridizing IoT with game theory for traffic rerouting and disease prediction is proposed. In this paper we use game theory to re-route the traffic that are predicted by using IOT. Most of the review exists about the distinctive medicinal services approaches utilized as a part of the loT, like, remote prosperity checking, U-social insurance, E-human services, Age-accommodating social insurance systems. This paper portrays and proposes a Health checking, rerouting and compelling human services observing framework outlined by utilizing the loT and also uses to game theory for predicting effected area. The test brings about this paper demonstrate the strong yield against different medicinal crises. In this framework to get the veracious assessment results, administering and measuring the wellbeing status of patient and to expand the energy of loT, the mix of microcontroller with sensors is exhibited.
\end{abstract}

Keywords: Watchwords versatile operator; GAME THEORY; body sensor; remote checking; web o/thing; shrewd human services;

\section{INTRODUCTION}

Information Technology has seen quick cross platform and cross practical advancements for example sensor, Nanotechnology and bio-businesses. In doctor's facilities, for the most part the E-healthcare framework is utilized for getting the data of patient. Air borne and water borne disease which commonly spread through air and water causes health issues. By the use of technology these critical situation can be tackled. One of such technique is proposed through the use of[1]. In the new age of innovation and remote correspondence, the enormous ascent in electronic gadgets like advanced mobile phones and tablets has turned into the most prevalent and essential instrument of everyday life.

Progressions in Internet of Things (loT) are generally utilized for interfacing the diverse gadgets like as sensors, apparatuses, vehicles and different articles. The apparatus suggested above may not be compatible with the game theory so some sort of interpretation mechanism is required to establish compatability. By utilizing loT, every one of these gadgets are associated with build up the correspondence amongst them and effectively get to the data[2].

The principle support of loT is to swell the benefit of Internet with remote control ability, information sharing, endless network and some more. The human service servers keep electronic restorative records of enrolled clients and give diverse administrations to patients, medicinal specialists and casual guardians. The patient's advisor can get to the information from office by means of internet and look at the patients' history, current indications and patient's reaction to a given treatment. Once wireless system involving IoT is configured, the social insurance server deals with the system, dealing with channel sharing [3], [4]. IoT contains specialized sensors placed over the body to grab the information about the disease and that information is stored within limited memory possessed by sensors. From the senors that information is transferred to advanced computing system including cloud.

The information fected from sensors is transferred to the concerned medical experts for analysis. The disease if predicted is conveyed to corresponding user. [5], [6]. Later numbers seized are used for measuring clarification. The measured checks are used to survey such all thoughtful of sickness will occur. The learning is noted for the amplified period. Part was right off the bat presented by Kevin Ashton in 1999, he associates the diverse sensors to physical question and transmits the data to the web. The loT mechanical know-how is these days served in express domains of presence together with computerized oilfield, living arrangement and erection robotization, insightful Grid, advanced clinical cure, astute haulage [7], [8]. Part science can yield gigantic learning about individual, time, things and space. Indeed, even as joining the present Web science and loT defame a radical utilize and enormous amount of region set on base charge sensors and remote correspondence. Web convention v6 and Cloud help the advance of amalgamation of web and loT [9]. It is investing additional possibilities of learning collecting, information treatment, and organization and different novel administrations. IPv6 is utilized to perceive a question which interfaces with loT by an exceptional tending to conspire. In provincial zone a large portion of the people groups does not get proper way to deal with wellbeing checking and facilities. So it is important to outline the powerful wellbeing observing framework. 
Normally, game theory certainly accepts that players have finish data about the diversion circumstance for the duration of the day and age. In this way, many diversion models expect that players are on immaculate discernment and can have enough capacities to act as indicated by their inclinations. In any case, this supposition is clearly not fulfilled under this present reality condition; tests have demonstrated that players don't generally act cleverly [10], [11]. What's more, customary diversion approaches endeavour to upgrade individual player's benefit. Nonetheless, the amusement players' gathering interest is by and large not upgraded and maybe not in any case very much served if every individual player advances his own conduct. This is on the grounds that improvement is an individual movement that depends on the teaching that every individual is focused on amplifying its own fulfilment without worry for the welfare of others.

In this segment shows the prologue to loT. The Internet of things (loT) is utilized as a part of various vehicles, cell phones, physical gadgets and so forth. The gadgets that uses the loT additionally called as keen gadgets or associated gadgets. The loT can be speak with various gadgets like as sensors, hardware programming, inserted frameworks, actuators, and so forth. Aside from these gadgets the GAME THEORY, scanner tags, QR codes, Ambient Intelligence and versatile Computing, utilizes the loT. These gadgets are utilized for gathering of the information and to trade of the information. The Global Standards Initiative on Internet of Things (loT-GSI) presents the loT in 2013 [12], [13]. Parcel enable things to be sense and precluded remotely crosswise over introduced arrange framework. So it makes the open door for more straightforward mix for continuous framework into digitized frameworks, and weighty in improved adequacy, rightness and financially savvy value. In the mean time loT works with sensors and actuators then this instruments fits request of besides normal gathering of cybertangible systems, which additionally include innovation for example clever transportation, shrewd urban areas and savvy houses. Each article is only specific by methods for its installed figuring framework yet is gifted to correspond inside helpful Internet establishment. Veterans figure that the loT will abide of about billions of things in future. Part gadgets are to permit remote wellbeing observing and crisis warning frameworks[14].

Game theory is an imaginative thought to understanding human practices from financial aspects to political science. Notwithstanding, because of the limited objectivity of diversion players, amusement hypothesis alone can't completely clarify human conduct and ought to supplement other key ideas championed by the behavioural controls.

Game theory is a branch of connected arithmetic that utilizations models to study associations with formalized impetus structures. These co operations are called "amusements". Diversion hypothesis can be utilized to clarify marvels in the regions of financial aspects, political hypothesis, transformative science and military technique, to give some examples. There are a few fixings which are basic to all diversions.

Players/Agents

[15]The principal things we need are at least two players. These can likewise be called specialists. These, as in a table game or game, are the general population, gathering, creature and so forth who really associate. These players have inclinations and objectives. That is to state, similar to all typical individuals, these specialists favour a few choices over another. Peaches over apples, bliss over misery - it doesn't generally make a difference WHAT they incline toward, yet they should have inclinations. These inclinations are utilized to work out precisely what the results of a diversion will be, on account of for the most part, players will pick choices that expansion the odds of getting their favoured results.

\section{FINDINGS OF PAPER}

$>$ Rerouting is suggested which is absent in earlier work

$>$ Online messages are not generated in existing approach that are used in proposed method

$>$ With game theory approach parallel operation has been performed that are not in earlier approaches.

$>$ Multiple diseases detection is possible.

\section{LITERATURE SURVEY}

In this segment the writing review of the proposed framework is available. The wellbeing checking framework with loT assumes a critical part. Parcel many research work is done on this theme, some of these are given underneath. In the paper exhibited by [14] plan the successful framework for shrewd urban areas by utilizing loT. The loT organize displays in this is cloud based structure and it utilizes the information administration. The framework design displays in this uses the three techniques in particular Data-based loT, Cloud-based loT and Network-based loT. These three procedures works under the distinctive principles, conventions and arrangements. The Crossbow's XMesh, IRIS, Crossbow's iMote, , QoS system, TCP/IP design, IPv6 , swarm sourcing, WSN, GAME THEORY rehearsed and inferred in this paper [16], in this paper has displayed a different arrangement to focal regulated established on loT. The loT introduces in this paper coordinates with various frameworks like Environment Integration Platform, Knowledge Base Systems, Context Management Framework, administrations supplier framework and healing center data framework. This auxiliary plan utilizes another convention called YOAPY, HOP, remote individual gadgets, 6LoWPAN, implanted frameworks [17], Marital equipment and GAME THEORY. Be that as it may, the convention YOAPY shows cheerful, however, this framework not give points of interest treatment of furthest point conditions. A keen locally established human services loT framework is displayed by [18]. For the locally situated medicinal services framework he utilizes a Medical Box(iMedBox) which is healthloT framework and iGATE way which goes about as a home social insurance entryway. Wearable sensors and keen pharmaceutical bundling (iMedPack)] are effectively coupled to the iMedBox by means of a different system, which is all around coordinated with a few displayed remote standards. The iMedPack is joined with the iMedBox by means of a game theory connection to bolster the clients with their masterminded solution. [19] introduced successful U-medicinal services framework by utilizing loT. The loT exhibits in this paper utilizes the versatile passage for the correspondence reason. It gives the detected data to a specialist or home restorative station. Yvette and [20], [21] proposed the U-medicinal 
services framework which utilizes the cell phones entryways and cell phones door for the specialized gadgets. These gadgets can be mounted on the patient's body at settled position. Cell phones secure detected perceptions transport by body sensor The Smart telephone is refined for giving out the data recognized the distance by means of multireason doors and figure customary perception. In this paper, the advanced mobile phone pass on perception to be inspected in reconnaissance focus. The advanced mobile phone will evaluate conceded detecting perception to develop catchphrases and boats to the focal framework.

In[22], the compelling development of various utilizations of loT and Smart Community are available. The design displays in this paper has three primary areas viz. Benefit Domain, Community Domain and Home Domain. These three spaces can handles the basic circumstance [2], debacle conditions and typical conditions. Considered technique exhibits in this paper utilizes diverse IEEE models, Ethernet Technology, distinctive cordless transmission measures like as $3 \mathrm{G}$ portable framework, body sensors, piconet and WiFi innovation, Ethernet and Home PNA. The proposed framework gives the veracity requests while whole transmission strategy and security. The paper exhibited by [12] proposed a compelling plan called 6LoWPAN. This engineering is composed by utilizing the loT for the Diabetic patients by utilizing ongoing glucose sensor. The 6LoWPAN design utilizes the Java dialect for the usage and utilizations the five layers: Application, Transport, Network, Adaptation and Link Physical layer. This plan having disadvantage of not producing ringer albeit patient's circumstance is not kidding. In [13], demonstrates the medicinal services screen framework by utilizing diverse remote sensor systems. The significant change of this framework in association with prior frameworks minimal vitality spending, broad correspondence scope to raise decision for enhanced patient's worth presence. The paper introduced by [14] an individual heart checking framework by utilizing a remote sensors and advanced mobile phones. This framework is intended for identifying the arrhythmias shows in the ECG flag. This framework has caution framework is available which gives the notice to the patient. The [15] proposes viable loT which gives the social insurance data of a patient with the assistance of Internet and by game theory. This game theory method is used to correspondence for the human services data framework for mechanizing managerial every day errands like consent care, evacuate and discharge subtle elements. In [17] proposes the successful human checking framework engineering. The primary favorable position of this framework is that this framework constant screen the physiological parameters especially of the develop or endless patient.

\section{PROPOSED WORK}

The proposed work uses the features of IoT and Game theory to enhance the performance disease prediction and rerouting. To detect the disease fuzzy rules are implemented. The dataset used is derived from the internet. Work is done in phases. Two phases are used. In first phase disease is detected and uploaded on cloud along with region information and in second phase game theory is applied for rerouting. Disease for convenience is referenced as " $A$ ". Rules are referenced through " $\mathrm{X}$ " and "Y". The fuzzy rules for disease prediction is listed as under

IF $\mathrm{X}>$ THRESHOLD $_{\mathrm{X}}$ AND $\mathrm{Y}>$ THRESHOLD $_{\mathrm{Y}}$ THEN DISEASE1 IS PREDICTED

IF $X>$ THRESHOLD $_{\mathrm{X}}$ THEN DISEASE2 IS DETECTED IF $Y>$ THRESHOLD $D_{Y}$ THEN DISEASE 3 IS DETECTED IF $\mathrm{X}<\mathrm{THRESHOLD}_{\mathrm{X}}$ AND $\mathrm{Y}<\mathrm{THRESHOLD}_{\mathrm{Y}}$ THEN NO DISEASE IS DETECTED

After checking disease, the information is conveyed to the user.

Utilization of Game theory then comes into picture. "Players" in the form of drivers is used. Information is fetched from cloud related to disease and infected area. Virtualized packets are transferred along multiple routes from position of the drivers. As the infection is detected, the driver corresponding to that route is blocked. The virtual packets reaching out to the destination detect the safe path. This information is conveyed to the other drivers by the way of Alerts and messages. The information about the infected roué is given through Google Maps. Visually displaying information provide graphical user interface along with plots on graphs for interactive working. Textual information is limited in this model for better performance. Parallel allocation of virtual players allow faster prediction of routes. 


\section{PROPOSED MODEL}

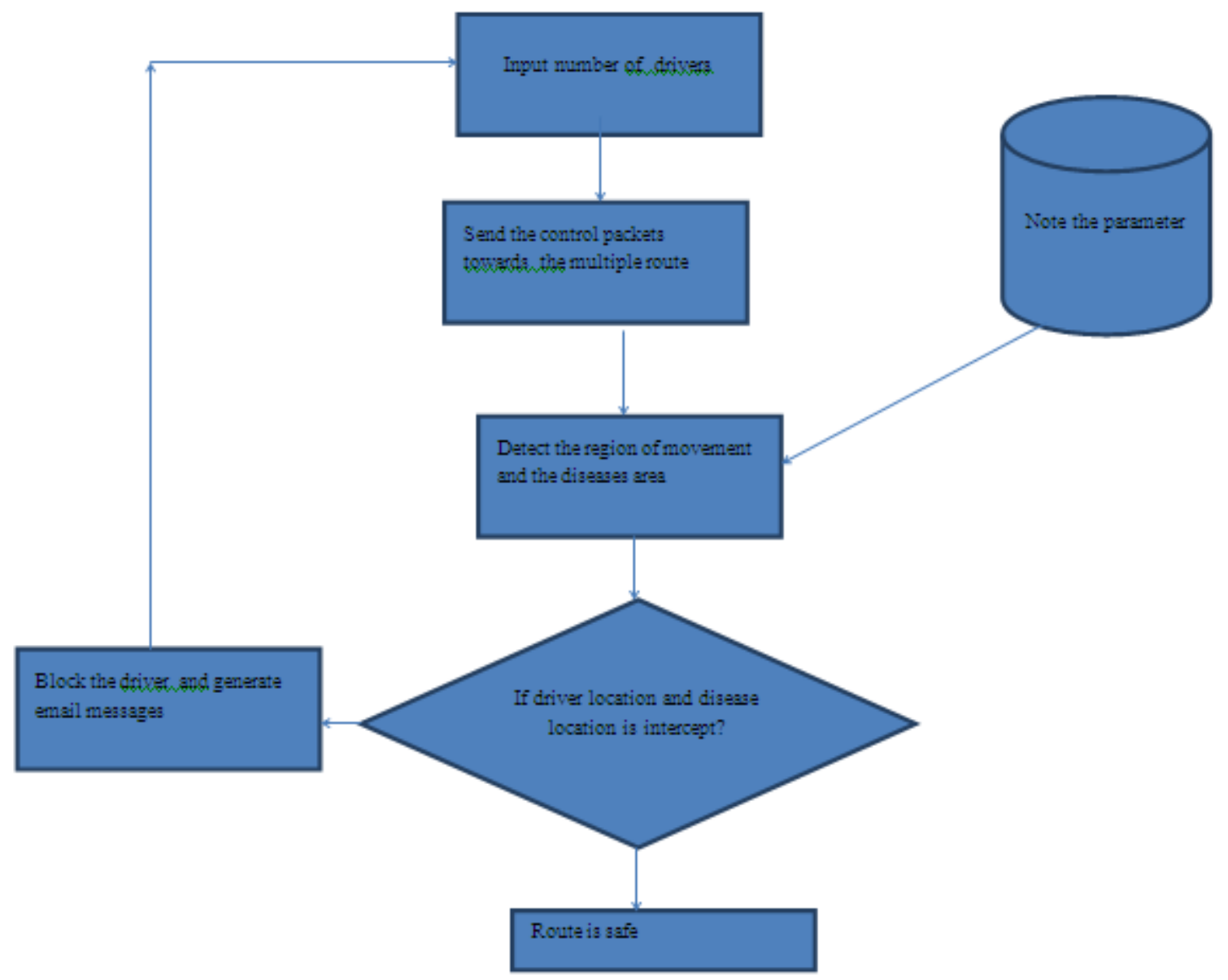

Figure 1: Proposed model using IoT and Game Theory

Algorithm-IoTGameTheory for Disease Prediction and Rerouting

- $\quad$ Phase 1

- Detect the disease using fuzzy rules by inputting parameters using sensors

- Filter $_{\mathrm{i}}=$ fuzzy_rules(input_parameters)

- If Filter $>$ Threshold

- Predict disease

- Goto step a

- Else

- No disease predicted and exit

- End of if

- a) Phase 2

- Apply virtual_players=drivers

- Send virtual players from driver position towards destination

- If infection $=$ =true

- block

- send alert message

- end of if

- show rerouting information on Google Maps

Next section describes the performance analysis of the proposed system compared to existing system.
Amritsar region. Performance comparison involve following parameters along with values

\section{PERFORMANCE ANALYSIS}

The proposed system gives the results in terms of disease detection and rerouting. Google maps are used for the purpose of rerouting. Region considered for prediction is of 
Table 1: Parameters Considered in proposed system

\begin{tabular}{|l|ll|ll|}
\hline $\begin{array}{l}\text { PERFORMANCE- } \\
\text { PARAMETERS }\end{array}$ & $\begin{array}{l}\text { SYSTEM WITHOUT GAME } \\
\text { THEORY }\end{array}$ & $\begin{array}{l}\text { PROPOSED WITH GAME } \\
\text { THERY }\end{array}$ & G \\
\hline DISEASE DETECTED & PARTICULAR & & MULTIPLE & \\
\hline REROUTING & ABSENT & & PRESENT & \\
\hline SPEED & SLOWER & & FASTER & \\
\hline USE OF GOOGLE MAPS & PRESENT & & \\
\hline
\end{tabular}

The google Map with rerouting information used in proposed system is shown as follows

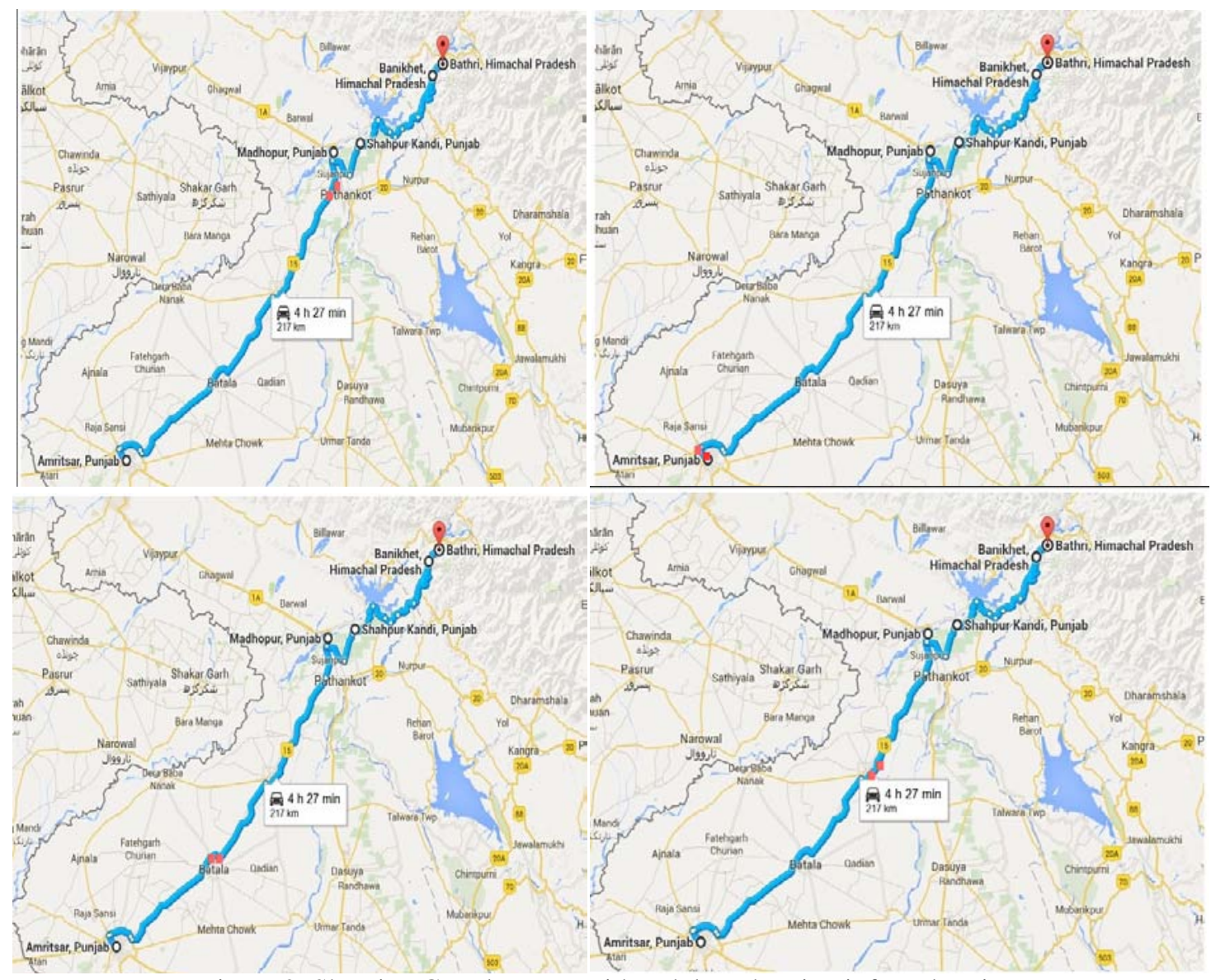

Figure 2: Showing Google Maps with red dots showing infected region

The proposed work according to analysis of work is better as compared to exiting work without rerouting.

\section{CONCLUSION}

For the ID of gadget and data handling of a hardware the GAME THEORY, WSN, and so on are utilized. IoTGameTheory is the proposed scheme of things. In this proposed framework we propose the data of a patient's wellbeing to the medicinal experts by means of advanced computing utilizing loT. This approach will righteously manage the anatomical contentions of the cases and any varieties in the pre-set parameters will trigger cautions been send to the therapeutic expert. This detection phase eliminate phase 1 . In phase 2, rerouting is suggested using Google Maps and applications of Game theory.

The performance analysis indicates better results in term of IoT and Game Theory.

\section{REFERENCES}

[1] P.-C. J. Chung, "Impacts of IoT and Wearable Devices on Healthcare," in Proceedings of the 12th International Conference on Advances in Mobile Computing and Multimedia - MoMM '14, 2014, pp. 2-2.

[2] B. D. Thomas, R. Mcpherson, G. Paul, and J. Irvine, "Consumption of Wi-Fi for IoT Devices," no. September, pp. 92-100, 2016.

[3] M. Kim and S. Chang, "A Consumer Transceiver for LongRange IoT Communications in Emergency Environments," vol. 62, no. 3, pp. 226-234, 2016.

[4] "11 Internet of Things (IoT) Protocols You Need to Know About.” [Online]. Available: https://www.rsonline.com/designspark/eleven-internet-of-things-iotprotocols-you-need-to-know-about. [Accessed: 28-Mar-2017].

[5] S. Abdelwahab, B. Hamdaoui, M. Guizani, and T. Znati, "R EPLISOM $\square$ : Disciplined Tiny Memory Replication for Massive IoT Devices in LTE Edge Cloud,” vol. 4662, no. c, 
2015.

[6] C. Perera, D. S. Talagala, C. H. Liu, S. Member, and J. C. Estrella, "Energy-Efficient Location and Activity-Aware OnDemand Mobile Distributed Sensing Platform for Sensing as a Service in IoT Clouds,” pp. 1-11, 2016.

[7] C. U. Scenarios and R. Architecture, "The advantages of IoT and Cloud applied to Smart Cities,” pp. 325-332, 2015.

[8] Z. T. Al-azez, A. Q. Lawey, T. E. H. El-gorashi, and J. M. H. Elmirghani, "Energy Efficient IoT Virtualization Framework with Passive Optical Access Networks,” pp. 1-4, 2016.

[9] K. N. Suchetha and H. S. Guruprasad, "Integration of IOT , Cloud and Big Data G LOBAL J OURNAL OF E NGINEERING S CIENCE AND R ESEARCHES,” no. October, 2016

[10] I. Transactions, O. N. Circuits, S. For, and V. Technology, "Introduction to the Special Section on Visual Computing in the Cloud $\square$ : Cloud Gaming and Virtualization," vol. 25, no. 12, pp. 1955-1959, 2015.

[11] Z. Xie, N. Sharath, and C. Wang, "A Game Theory Based Resource Scheduling Model for Cost Reduction in Home Health Care,” pp. 1800-1804, 2015.

[12] D. Marculescu, N. H. Zamora, P. Stanley-marbell, and R. Marculescu, "Fault-Tolerant Techniques for Ambient Intelligent Distributed Systems-," pp. 348-355, 2003.

[13] D. J. Cook, J. C. Augusto, and V. R. Jakkula, "Ambient intelligence $\square$ : Technologies , applications , and opportunities," Pervasive Mob. Comput., vol. 5, no. 4, pp. 277-298, 2009.

[14] A. Mathew, F. A. S. A, H. N. Pooja, and A. Verma, "Smart
Disease Surveillance Based on Internet of Things ( IoT ),” vol. 4, no. 5, pp. 180-183, 2015.

[15] D. Yang, X. Fang, and G. Xue, "Game Theory in Cooperative Communications.”

[16] L. Catarinucci, D. de Donno, L. Mainetti, L. Palano, L. Patrono, M. L. Stefanizzi, and L. Tarricone, "An IoT-Aware Architecture for Smart Healthcare Systems,” IEEE Internet Things J., vol. 2, no. 6, pp. 515-526, Dec. 2015.

[17] H. J. La, "Extensible Disease Diagnosis Cloud Platform with Medical Sensors and IoT Devices,” pp. 371-378, 2015.

[18] J. Gubbi, R. Buyya, and S. Marusic, "Internet of Things ( IoT ): A Vision , Architectural Elements , and Future Directions," pp. 1-28.

[19] S. Zhao, L. Yu, and B. Cheng, "An Event - driven Service Provisioning Mechanism for IoT ( Internet of Things ) System Interaction,” vol. 3536, no. c, 2016.

[20] V. M. Rohokale, N. R. Prasad, and R. Prasad, "A cooperative Internet of Things (IoT) for rural healthcare monitoring and control,” in 2011 2nd International Conference on Wireless Communication, Vehicular Technology, Information Theory and Aerospace \& Electronic Systems Technology (Wireless VITAE), 2011, pp. 1-6.

[21] T. Salman and R. Jain, "Networking Protocols for Internet of Things,” pp. 1-28, 2013.

[22] S. M. Riazul Islam, M. Humaun Kabir, and M. Hossain, "The Internet of Things for Health Care: A Comprehensive Survey,” IEEE Access, vol. 3, pp. 678-708, 2015. 